This item was submitted to Loughborough's Research Repository by the author.

Items in Figshare are protected by copyright, with all rights reserved, unless otherwise indicated.

\title{
Association between depression, lung function and inflammatory markers in patients with asthma and occupational asthma
}

PLEASE CITE THE PUBLISHED VERSION

https://doi.org/10.1097/JOM.0000000000001562

\section{PUBLISHER}

Lippincott, Williams \& Wilkins

\section{VERSION}

AM (Accepted Manuscript)

\section{PUBLISHER STATEMENT}

This is a non-final version of an article published in final form in Journal of Occupational and Environmental Medicine, 61 (6), pp.453-460, doi: 10.1097/JOM.0000000000001562.

\section{LICENCE}

CC BY-NC-ND 4.0

\section{REPOSITORY RECORD}

Paine, Nicola, Maryann F. Joseph, Simon L. Bacon, Cassandre A. Julien, Andre Cartier, Blaine Ditto, Helene Favreau, and Kim L. Lavoie. 2019. "Association Between Depression, Lung Function and Inflammatory Markers in Patients with Asthma and Occupational Asthma”. Loughborough University. https://hdl.handle.net/2134/37441. 


\title{
Association between Depression, Lung Function and Inflammatory Markers in
}

\section{Patients with Asthma and Occupational Asthma}

\author{
Nicola J. Paine, $\mathrm{PhD}^{1,2}$, Maryann F. Joseph, $\mathrm{PhD}^{2}$, Simon L. Bacon, $\mathrm{PhD}^{2,3}$, \\ Cassandre A. Julien, $\mathrm{BSc}^{2,4}$, André Cartier, $\mathrm{MD}^{2,5}$, Blaine Ditto, $\mathrm{PhD}^{6}$, Hélène Favreau, \\ $\mathrm{PhD}^{2}$, Kim L. Lavoie, $\mathrm{PhD}^{2,4}$ \\ ${ }^{1}$ School of Sport, Exercise and Health Sciences, Loughborough University, \\ Loughborough, United Kingdom; ${ }^{2}$ Montreal Behavioural Medicine Centre, Research \\ Centre, Centre intégrée universitaire de services de santé et de services sociaux du Nord- \\ de-l'île-de-Montréal, Hôpital du Sacré-Cœur de Montréal, Montréal, Canada; ${ }^{3}$ Department \\ of Exercise Science, Concordia University, Montreal, Canada; ${ }^{4}$ Department of \\ Psychology, University of Québec at Montréal (UQAM), Montréal, Canada; ${ }^{5}$ Department \\ of Medicine, Université de Montréal, Montréal, Canada; ${ }^{6}$ Department of Psychology, \\ McGill University, Montréal, Canada;
}

Running title: Depression \& Inflammation in Occupational Asthma

Corresponding author: Kim L. Lavoie, PhD, Montreal Behavioural Medicine Centre, Centre Intégré universitaire de santé et de services sociaux du Nord-del'île-de-Montréal Hôpital du Sacré-Cœur de Montréal, J-3190, 5400 Gouin West, Montreal, Quebec, H4J 1C5, Canada. Tel: 514-338-2222 (3709); Fax: 514-338-3123; Email: lavoie.kim@uqam.ca

Conflicts of Interest and Sources of Funding: The authors have no conflicts of interest to disclose. Funding support for this study was provided by the Institut de recherche en santé et sécurité au travail (IRSST) (KLL) and the Asthma in the Workplace Center (KLL, SLB). Postdoctoral Fellowship support was provided by Fonds de la recherche du Quebec - Sante (FRQS) (NJP) and the Canadian Institutes of Health Research (CIHR [MFE146764]) (NJP). Salary support for this work was provided by the Fonds de la recherche du Quebec - Sante (FRQS) (KLL \& SLB) and the Canadian Institutes of Health Research (CIHR) (KLL \& SLB). Doctoral scholarship support was provided by FRQS (HF, $\mathrm{MJ})$, the Social Sciences and Humanities Research Council (SSHRC) (MJ), and Frederick Banting and Charles Best Doctoral Training Scholarship - Canadian Institutes of Health Research (CIHR) (CAJ).

Word count: 6,262 ;

Number of Figures: 2; Number of Tables: 3

This is a non-final version of an article published in final form in: $\mathrm{J}$ Occup Environ Med. 2019; Publish Ahead of Print. Epub March 1 2019. doi: 10.1097/JOM.0000000000001562 The final peer-review manuscript can be found at: https://journals.Iww.com/joem/Fulltext/publishahead/Association_Between_Depression,_Lu ng_Function_and.98477.aspx 


\section{Abstract}

Objective: Depression is associated with autonomic and immune dysregulation, yet this remains poorly explored in asthma. We assessed associations between depressive disorder, lung function, and inflammatory markers in patients under investigation for occupational asthma (OA).

Methods: 112 patients under investigation for OA (60\% men) underwent a psychiatric interview to assess depressive disorder, and spirometry, a methacholine test, sputum induction and specific inhalation challenge (SIC) to assess OA. Blood and sputum inflammatory markers were assessed.

Results: There was a statistically significant association between depressive disorder $(p=.0195)$ and $\mathrm{FEV}_{1}$ responses, with the drop in $\mathrm{FEV}_{1}$ post-SIC smaller in patients with OA and depression, versus OA with no depression, $(p<.001)$.

Conclusions: The presence of depressive disorder may influence $\mathrm{FEV}_{1}$ in patients with OA, which may be via autonomic pathways. However, further studies are warranted in order to determine the mechanisms which underlie these effects.

Keywords: inflammation, depression, occupational asthma

Running title: Depression and Inflammation in Occupational Asthma 


\section{Abbreviations and Acronyms}

ANS - Autonomic Nervous System

BMI - Body Mass Index

CRP - C-reactive Protein

DSM-IV - Diagnostic and Statistical Manual of Mental Disorders

$F E V_{1}-$ Forced Expiratory Volume in 1 second

ICS - Inhaled Corticosteroids

IL-6 - Interleukin-6

MDD - Major Depressive Disorder

NA - No Asthma

Non-OA - non-Occupational Asthma

OA - Occupational Asthma

$\mathrm{PC}_{20}$ - a significant fall in Forced Expiratory Volume in 1 second $\left(F E V_{1}\right)$ which was greater than $20 \%$

PRIME-MD - Primary Care Evaluation of Mental Disorders

SCID - Structured Clinical Interview for DSM

SIC - Specific Inhalation Challenge 


\section{Introduction}

Asthma is a chronic respiratory disease which is characterized by airway inflammation and reversible airflow limitation ${ }^{1}$, and is one of the most common diseases in the world ${ }^{2}$. Between 10 to $25 \%$ of new adult onset asthma is attributed to work exposure ${ }^{3}$. Asthma related to work can be classified as either work-aggravated asthma or occupational asthma, the latter being caused by either immunologically-mediated sensitization or by exposure to high concentrations of an irritant. Classically, occupational asthma (OA) refers to sensitization and is defined as a respiratory disease with variable airflow limitation and/or airway hyperresponsiveness in response to exposure to stimuli present in an individual's work environment, and not to stimuli encountered outside the workplace ${ }^{4}$. The most common causal agents in developed countries are isocyanates in paints and industrial processes, flour, chemical agents (e.g., fluxes, enzymes), wooddusts, drugs, proteins (e.g., plant and animal-based), metals, resins and glues, latex, cereals and grains ${ }^{4,5}$.

Psychological stress, which refers to the emotional and physiological reactions experienced when an individual confronts a situation in which the demands go beyond their coping resources ${ }^{6}$, is also believed to contribute to the burden of disease in both asthma and $\mathrm{OA}^{7}$. Indeed, there is a disproportionately high rate of depression (which reflects excess feelings of sadness and/or loss of interest in performing the activities of daily life) ${ }^{8}$ among patients with asthma and OA. In an early study, we found depressive symptoms causing clinically significant levels of psychological distress in almost half (47.5\%) of 40 confirmed subjects with $\mathrm{OA}^{9}$. More recently, we have reported rates of depressive disorders (including major depression, minor depression and dysthymia, which reflect clinically significant levels of depression $^{8}$ ) among asthma and OA patients of $20 \%$ and $29 \%$ respectively ${ }^{10,11}$. Given that depression has been associated with increased asthma severity, increased use of emergency services, increased symptoms reporting, poorer pulmonary function, lengthier hospital stays, increased use of reliever medication, worse asthma control, and worse asthma-related quality of 
life among asthmatics in general ${ }^{12-16}$, it has been suggested that depression may also play a role in OA.

Depression has been shown to be associated with dysregulated autonomic and immune responses ${ }^{17-22}$, and there is some evidence linking stress-related depression with altered autonomic function (e.g., decreased lung function) in asthmatic children ${ }^{23}$ and increased inflammatory responses in atopic asthmatics ${ }^{24}$. However to our knowledge, no studies have assessed how depression affects these responses in patients with OA. The objective of the current study was to explore the associations between depression (depressive disorder), lung function, and inflammatory markers in patients under investigation for occupational asthma (OA) with eventual diagnoses of OA, non-Occupational asthma (Non-OA) and no asthma (NA).

\section{Methods}

Participants

This is a sub-study of a prospective cohort study where aspects of the methods have been reported elsewhere ${ }^{11,25}$. Briefly, 219 consecutive participants who had been refered for possible work-related asthma were recruited from the outpatient asthma clinic of the CIUSSSNIM (formerly Hôpital du Sacré-Coeur de Montréal) from December 2004 to December 2008. Participants were eligible if they were between 18 and 75 years of age and fluent in English or French. Participants were excluded if they had a previously diagnosed comorbid medical condition conferring greater risk for morbidity than asthma (e.g., lung cancer), severe psychopathology (e.g., schizophrenia) or substance abuse. Of the 247 participants who presented to the clinic for investigation of OA during the study period, 241 were approached to participate, and 219 agreed to be in the main study. For this sub-study, only participants who were diagnosed as having OA, non-Occupational asthma (Non-OA) or no asthma (NA) were included, which yielded a final sample of 112 participants (see Figure 1). Final diagnosis of OA, Non-OA and NA was determined based on FEV ${ }_{1}$, clinical characteristics including blood cell 
counts and variability in the responses to methacholine assessment. This study was approved by the research ethics committee of CIUSSS-NIM (formerly Hôpital du Sacré-Coeur de Montréal), and written informed consent was obtained from all participants.

\section{Procedure and Measures}

Sociodemographic and Medical Information

Sociodemographic information and medical history (including medications) was obtained using a brief structured interview. Participants self-reported smoking history and height and weight were used to calculate body mass index (BMI). Adherence to daily ICS medication (if applicable) was also self-reported. All clinical data were verified by medical chart review.

\section{Depression}

Participants underwent a brief (approximately 15 minute) structured psychiatric interview, the Primary Care Evaluation of Mental Disorders (PRIME-MD) ${ }^{26}$ to assess the presence of a depressive disorder including major depressive disorder (MDD) and other depressive disorders (minor depression, dysthymia). The PRIME-MD generates clinical diagnoses based on Diagnostic and Statistical Manual of Mental Disorders (DSM-IV) ${ }^{27}$ criteria, and has demonstrated reliability (Kappa $=0.71)$, sensitivity $(83 \%)$ and specificity $(88 \%)$ for the diagnosis of MDD comparable to longer interviews such as the Structured Clinical Interview for DSM, (SCID) ${ }^{26,28}$. The interview was administered by a single, trained clinical research assistant who was supervised by a licensed clinical psychologist (KLL).

\section{Physiological Measures: Spirometry, Blood and Sputum}

\section{Spirometry and OA Evaluation}

The full procedure has been described fully elsewhere ${ }^{29}$, and is described briefly below. Firstly, spirometry was assessed per the American Thoracic Society guidelines ${ }^{30}$. Methacholine 
inhalation challenge was performed with a Wright nebulizer (output $0.14 \mathrm{~mL} / \mathrm{min}$ ) at tidal volume breathing for 2 minutes as described elsewhere ${ }^{31}$. Sputum was induced using inhalations of increasing concentrations of hypertonic saline solution (3-5\%) and then processed ${ }^{32}$. Blood was drawn in every participant before the SIC challenge to obtain a blood cell count ${ }^{29}$. Blood measures included: total white blood cell count, and the cell counts for neutrophils, eosinophils and lymphocytes. Sputum measures included: total cell count by weight $\left(10^{6} \mathrm{c} / \mathrm{ml}\right)$, and the respective total cell counts and percentage counts of neutrophils, eosinophils, and lymphocytes.

Specific inhalation challenges (SIC) were performed in the laboratory or in the workplace 33. On the first testing day, participants were exposed to a sham/inert substance (e.g., lactose or thinner) for 30 minutes to ensure that stability of their spirometry. Subsequently, participants were exposed to the occupational agent suspected of causing their symptoms. If the SIC to this suspected substance was negative or if exposure in the workplace could not be replicated in the laboratory, the participants returned to their workplace with a respiratory technologist where their respiratory function was assessed hourly over a 7-hour period for 2 consecutive days. A positive SIC test and diagnosis of occupational asthma (OA) was defined by a significant fall in Forced Expiratory Volume in 1 second $\left(\mathrm{FEV}_{1}\right)$ which was greater than $20 \%$ after exposure $\left(\mathrm{PC}_{20}\right)$, inconjunction with other characteristics including variation of repeated methacholine tests, increased cellularity of blood and eosinophil profile (e.g., heightened immune profile in blood). At the end of the control day, and at the end of the exposure day a methacholine challenge and sputum induction were completed. Long-acting $\beta 2$-agonists and short-acting $\beta 2-$ agonist were stopped for 72 hours and 8 hours respectively before the challenge; inhaled corticosteroids (ICS) use was maintained throughout the SIC test, however the total daily dose was administered 12 hours prior to the SIC or in the evenings of the SIC days. At the end of the OA evaluation process, participants were classified as having occupational asthma (OA); pre-existing or non-occupational asthma (Non-OA); or no asthma (NA) (further 
information as to diagnosis procedure has been described fully elsewhere ${ }^{34}$ ). Those meeting diagnostic criteria for another non-asthma-related diagnosis (e.g., rhinitis, hyperventilation syndrome, eosinophilic bronchitis, $n=54$ ) were excluded from the present sub-study, plus participants who did not complete an adequate SIC $(n=30)$ (see Figure 1).

\section{Data Analysis}

All analyses were completed using SAS version 9.4 (Cary, NC). Prior to statistical analysis, the distributions of variables were examined. Variables demonstrating notable skewness were log transformed to normalize the distribution. Means (SD) and proportions (percentages and numbers) were presented to describe continuous and categorical variables, respectively. A series of Chi-square statistics and General Linear Models were used to determine demographic and sample characteristics for categorical and continuous variables respectively. Using Rubin's rules ${ }^{35}$ our missing data analysis procedures used multiple imputation ${ }^{36}$ with missing at random (MAR) assumptions. Using the PROC MI method of multiple multivariate imputation in SAS, we independently analyzed 20 copies of the data. PROC MIANALYZE was used according to Harrell's guidelines ${ }^{37}$. Significance was set at $p$ $<.05$ for all analyses. The primary analyses were general linear models (GLMs) examining the association between depressive disorder, final asthma diagnosis (OA; non-OA; NA) and our physiological outcomes of interest. These were 1) Pulmonary function (measured as FEV 1 reactivity, and PC20 responses to methacholine); 2) Mean percentage of sputum cell differentials percentages of neutrophils, lymphocytes and eosinophils in sputum); and 3) Total mean blood cell differentials (total blood cell counts for neutrophils, lymphocytes and eosinophils). These analyses were adjusted for age, sex, smoking status, symptoms post SIC test, and prescribed dose of ICS. Each physiological parameter was the dependent variable; the independent variables were depressive disorder and final asthma diagnosis. The potential interacting effects between depressive disorder and final asthma diagnosis were also assessed. 


\section{Results}

Socio-demographic and medical characteristics

Demographic characteristics are summarized in Table 1 as a function of asthma group; there were group differences in the proportion of participants taking ICS and long acting asthma medications and in ICS dose, with more participants in the OA and Non-OA groups being prescribed asthma medications and having higher ICS doses than those in the NA group. As expected, there were also differences in the fall in $\mathrm{FEV}_{1}$ during the SIC challenge and the total cell counts for eosinophils, with those in the OA group having greater drops in $\mathrm{FEV}_{1}$ and higher eosinophil cell counts relative to those in the NA group. Further details on sputum immune concentrations can be found in supplementary table 1.

\section{Pulmonary Function}

Analyses were undertaken to determine the relationships between depressive disorder, asthma diagnosis, and pulmonary function (measured as $\mathrm{FEV}_{1}$ reactivity, and $\mathrm{PC} 20$ responses to methacholine). As expected (see supplementary table 2), there was a main effect of diagnostic group $(\beta=7.56 \pm 0.95 ; 95 \% \mathrm{Cl}=5.68-9.45 ; p<.001)$ on $\mathrm{FEV}_{1}$ responses with the greatest decreases in $\mathrm{FEV}_{1}$ observed in the OA group. There were also main effects of depressive disorder $(\beta=3.59 \pm 1.53 ; 95 \% \mathrm{Cl}=0.57-6.60 ; p=.0195)$ on $\mathrm{FEV}_{1}$ responses. Participants with a depressive disorder exhibited significantly smaller $F E V_{1}$ decreases $F E V_{1}$ compared to those without a depressive disorder $(-7.03 \% \pm 6.56 \%$ vs $-11.69 \% \pm 10.24 \%)$, irrespective of asthma diagnosis group. Analysis of the impact of depression in each group revealed that in participants with $\mathrm{OA}$, we observed a specific effect of depressive disorder on $\mathrm{FEV}_{1}$ responses (OA without depression vs OA with depression; $-21.5 \% \pm 8.50 \%$ vs $-12.1 \% \pm$ 9.70; $p$ <.001). This suggests that among OA participants, having a depressive disorder 
attenuates (decreases) $\mathrm{FEV}_{1}$ drops in response to SIC challenge. There was no specific effect of depressive disorder on $\mathrm{FEV}_{1}$ in either the Non-OA or NA participants.

In participants with a depressive disorder, we observed specific differences in $\mathrm{FEV}_{1}$ responses between participants with OA and NA $(-12.05 \% \pm 9.70 \%$ vs $-4.89 \% \pm 1.88 \% ; p=.025)$, with unsurprisingly larger decreases in $\mathrm{FEV}_{1}$ observed in OA participants. Likewise, there were differences in $\mathrm{FEV}_{1}$ between participants with OA and Non-OA $(-12.05 \% \pm 9.70 \%$ vs $-4.55 \% \pm$ 2.75\%; $p=.003$ ), where again OA participants had greater decreases in FEV 1 . There were no differences seen between the $\mathrm{FEV}_{1}$ responses of participants with depression and Non-OA or NA (Non-OA $=-4.55 \% \pm 2.75 \%$ vs $-4.98 \% \pm 1.88 \%(O A) ; p=.43)$. As seen in Figure 2 , in participants without a depressive disorder, there was a similar pattern of response. There was no depressive disorder by diagnostic group interaction effects $(p>.05)$.

There were no main effects of depressive disorder on $\mathrm{PC}_{20}$ responses $(\beta=0.01 \pm 0.11$; $95 \% \mathrm{Cl}=-0.20-0.22 ; p=.92)$, however there was a main effect of diagnostic group $(\beta=0.27 \pm$ $0.07 ; 95 \% \mathrm{Cl}=0.12-0.42 ; p=.0003$ ) revealing, unsurprisingly, higher (better) LogPC 20 responses in participants with NA in contrast to participants with OA $(p<.001)$ and Non-OA $(p=$ .003). There were no differences in $\mathrm{PC}_{20}$ responses from pre-SIC to post-SIC testing between participants with OA vs Non-OA $(p=.43)$ and there was no interaction between depressive disorder and diagnostic group $(p>.05)$.

\section{Immune Parameters}

\section{Sputum cell differentials}

Mean sputum cell differentials can be found in Table 2, with total sputum cell counts in Supplementary table 3. Depressive disorder was not associated with pre-SIC sputum total cell counts $(\beta=-0.28 \pm 1.35 ; 95 \% \mathrm{Cl}=-2.94-2.37 ; p=.83)$. Depressive disorder was also not associated with $\%$ counts for neutrophils $(\beta=1.48 \pm 4.88 ; 95 \% \mathrm{Cl}=-8.08-11.05 ; p=.76)$, 
eosinophils $(\beta=0.09 \pm 1.87 ; 95 \% \mathrm{Cl}=-3.57-3.75 ; p=.96)$ or lymphocytes $(\beta=0.49 \pm 0.40$;

$95 \% \mathrm{Cl}=-0.29-1.27 ; p=.22)$. There were no main effects of diagnostic group for sputum total cells $(\beta=-1.05 \pm 0.81 ; 95 \% \mathrm{Cl}=-2.66-0.55 ; p=.20)$. For the percentage of immune markers that were measured in sputum, there were no main effects of diagnostic group for \% sputum neutrophils $(\beta=-3.33 \pm 3.12 ; 95 \% \mathrm{Cl}=-9.45-2.79 ; p=.29)$, or $\%$ lymphocytes: $(\beta=-0.12 \pm 0.25$; $95 \% \mathrm{Cl}=-0.61-0.37 ; p=.62)$, but there was a main effect for $\%$ eosinophils, $(\beta=-4.96 \pm 1.17$; $95 \% \mathrm{Cl}=-5.55--3.88 ; p<.001)$. Post-hoc analyses showed lower $\%$ eosinophils in participants with Non-OA and NA compared to OA $(p<.001)$. However, there were no significant differences in $\%$ eosinophils in participants with Non-OA vs NA $(p=.86)$.

Diagnosis group was not associated with pre-SIC sputum total cell counts $(\beta=-1.05 \pm 1.35$; $95 \% \mathrm{Cl}=-2.66-0.55 ; p=.20)$. There were no interactions between depressive disorder and diagnostic group for any of the sputum cell counts or percentages ( $p$ 's $>.05$ ) (Table 2).

\section{Blood cell differentials}

Mean blood cell differentials can be found in Table 3. There was a main effect of depressive disorder for pre-SIC neutrophils and lymphocytes. Depressive disorder was associated with higher blood neutrophils $(\beta=0.05 \pm 0.02 ; 95 \% \mathrm{Cl}=0.01-0.10 ; p=.013)$ and lower lymphocyte cell counts $(\beta=-0.05 \pm 0.02 ; 95 \% \mathrm{Cl}=-0.09--0.02 ; p=.004)$. Post-hoc analyses showed that there was also a marginal effect of depressive disorder for neutrophils in participants with NA, with higher neutrophils in those with a depressive disorder compared to those with OA or Non-OA $(p=.058)$. There was a similar effect of depressive disorder on lymphocyte counts in participants with NA but not OA or Non-OA $(p=.019)$, with lower lymphocytes seen in those with a depressive disorder. There was no relationship between depressive disorder and eosinophil counts $(\beta=0.002 \pm 0.006 ; 95 \% \mathrm{Cl}=-0.01-0.01 ; p=.70)$.

Similarly, there was a main effect of asthma diagnosis for neutrophils and lymphocytes. These effects are summarized in Table 3. There was a relationship between asthma diagnosis 
group and lymphocytes $(\beta=0.03 \pm 0.01 ; 95 \% \mathrm{Cl}=0.01-0.05 ; p=.010)$, where lymphocytes were lower for OA compared to NA $(p=.011)$ but not for OA vs Non-OA $(p=.11)$ or Non-OA vs NA $(p=.79)$. There was also a relationship between asthma diagnosis and neutrophils, $(\beta=-$ $0.028 \pm 0.01 ; 95 \% \mathrm{Cl}=-0.06--0.001 ; p=.044)$, with a similar pattern observed whereby neutrophils were higher for OA compared to NA $(p=.054)$ but not for OA vs Non-OA $(p=.09)$ or Non-OA vs NA $(p=.72)$. There was no effect of group on eosinophils cell count $(\beta=-0.00 \pm 0.00$; $95 \% \mathrm{Cls}=-0.01-0.01 ; p=.99)$. There was no depressive disorder by asthma diagnosis group interaction effects $(p>.05)$.

\section{Discussion}

The aim of the study was to examine the association between depressive disorder and lung function and inflammatory responses in participants with OA, Non-OA, and NA. In summary, participants with (vs without) a depressive disorder exhibited smaller decreases in $\mathrm{FEV}_{1}$ responses (i.e., the reduction in $\mathrm{FEV}_{1}$ was greater in patients without depressive disorder). Further, we found that in participants with OA, having a depressive disorder was associated with lower decreases in $\mathrm{FEV}_{1}$ post-SIC, which was not seen in the other two diagnostic groups. Having a depressive disorder was also associated with increased blood neutrophils and decreased blood lymphocytes, but only among those without asthma; a pattern that was not observed in sputum. Overall, these results suggest that depression is associated with attenuated Autonomic Nervous System (ANS) responses, particularly in participants with OA, and with dysregulated immune responses that are more pronounced in participants without asthma (but who present with asthma-like symptoms by virtue of them being under investigation for OA). This suggests that among those without asthma, depression may be accounting for at least some aspects of asthma-like symptom presentation via depression-related immune pathways ${ }^{38}$. 


\section{Relationships between physiological measures and depression}

Our results show that in participants with a depressive disorder and OA, that there was a smaller drop in $\mathrm{FEV}_{1}$ that would seem to reflect less severe or attenuated airway responses. This contradicts previous studies showing that depression tends to increase or enhance ANS-driven responses in asthmatics ${ }^{23}$. This suggests that our findings point to a dysregulation of the ANS, rather than a upregulation of the ANS, which is a key characteristic of asthma ${ }^{39}$ and consistent with some manifestations of depression ${ }^{40-43}$. For example, depression is associated with both increases and decreases in sleep, appetite and weight; it is also associated with both psychomotor agitation and retardation ${ }^{8}$. It is possible that among asthmatics whose ANS is already upregulated, that depression may interfere with this, resulting in an attenuation of ANSdriven responses ${ }^{44}$ including $\mathrm{FEV}_{1}$. Depression may also attenuate $\mathrm{FEV}_{1}$ drops through behavioral pathways. A cardinal feature of depression is decreased motivation and fatigue ${ }^{8}$, which may have influenced performance of spirometry which is in part behaviorally mediated ${ }^{30}$. Depression has been previously shown to interfere with the measurement of lung volumes ${ }^{45}$, so it is possible that depressed participants may have been less performant during spirometry testing, resulting in lower drops in $\mathrm{FEV}_{1}$. Further studies directly assessing spirometric performance in depressed vs. non-depressed participants and its impact on diagnosis and outcomes are needed.

There was no association between depressive disorder and $\mathrm{PC}_{20}$ responses post-SIC, suggesting similar levels of airway obstruction and hyper-reactivity across participants with and without depression regardless of asthma status. It should be noted that airway obstruction in asthma is variable such that mild asthmatics often display normal spirometry between periods of acute exacerbations. Indeed, most participants under investigation for OA present with normal lung function when $\mathrm{FEV}_{1}$ and FVC are initially measured in the clinic ${ }^{46}$. Furthermore, even confirmed cases of OA may present with normal bronchial reactivity as captured by $\mathrm{PC}_{20}$ in the clinic, especially if tested after several days away from the causal workplace environment ${ }^{46,47}$. 
Therefore it is possible that in a non-clinic or 'real life' setting that there is an effect of depression but that this is not evident in our results. Other studies have also shown no effect of depression on $\mathrm{PC}_{20}$ responses in asthma patients ${ }^{48,49}$, so it is perhaps not surprising that we did not see this in our participants who were undergoing assessment for OA.

Interestingly, immune analyses demonstrated that having a depressive disorder was associated with an increased number (and proportion) of neutrophils and a decreased number (and proportion) of lymphocytes in blood pre-SIC challenge. However, this was only observed in participants without asthma and not seen in participants with OA or Non-OA. These findings are consistent with previous depression research in the general population ${ }^{50,51}$ and with the general finding that depression is linked to increases in immune markers, however this was not the case for lymphocytes in our sample which is counter to previous research ${ }^{50,52,53}$. Our results add to the growing evidence that there is a relationship between depression and airway immune markers in asthma populations ${ }^{54,55}$. However, these immune markers were derived from preSIC assessments of blood and sputum, and as such our results need to be interpreted cautiously relative to the rest of the literature.

Surprisingly, we did not observe any significant relationships between depressive disorder and sputum measures of inflammation post-SIC challenge. To our knowledge, this is the first study to examine relationships between depressive disorder and sputum lymphocyte populations in both OA and Non-OA populations. While blood lymphocytes may provide information about global immune alterations, sputum lymphocytes are of interest in asthma research because they provide more direct observation of immune function in the airways. Our results are somewhat contrary to those of Liu et al, who assessed the inflammatory responses during antigen challenge among medical students with asthma during a "high stress" period (exam stress) ${ }^{56}$. Liu and colleagues found that both sputum eosinophils and eosinophil derived neurotoxin levels increased in response to antigen challenge during the stress period, which were observed in the context of significantly increased levels of anxiety and depression ${ }^{56}$. Thus, 
it was surprising to see no relationship to eosinophil counts in relation to depression in this study. One possible explanation is that we were investigating responses to SIC tests rather than antigen challenge, where patterns of physiological responses may differ. Additionally, given that both asthma and depression are inflammatory diseases, it is possible that in participants with both depression and asthma, there is no direct relationship with early cascade immune markers as the immune system is already flooded with more late-phase cascade inflammatory markers. However, as it was beyond the scope of the study to examine inflammatory markers such as Interleukin-6 (IL-6) and C-reactive protein (CRP), which are more typically related to depression 57 , we cannot ascertain if this theory is accurate, and further investigation in participants with different asthma diagnoses is needed to help determine the relationships to sputum inflammation and depression in asthma.

Our study contains some potential limitations that should be noted. Firstly, as the study is cross-sectional, future longitudinal research will be required to examine the potential causal effects of depression over time and the possible mediating role of immune parameters on measures of respiratory function. To explore this, one direction for future studies could be to objectively measure physiological responses in depressed versus non-depressed participants with OA, Non-OA or NA, capturing respiratory and immune function before and after laboratory exposure to a psychological stressor or a physiological challenge (e.g., antigen exposure). Our inability to examine additional markers of inflammation (e.g., IL-6, CRP) which are more typically assessed in the context of depression should also be considered a limitation.

Despite these limitations, the present study also has several important strengths. It is the first to examine depressive disorder in relation to clinical and physiological characteristics in participants with OA and Non-OA compared to NA. Though our sample size is modest at 112, it is considered very large for this highly specialized patient population (participants under investigation for OA). Relative to the broader asthma literature, this sample was well defined and included verified medication prescriptions and objectively assessed asthma and depression 
diagnoses. All our measures (blood, sputum, SIC testing) were completed in a specialized clinic, which enhances the validity of our diagnoses. Finally, analyses adjusted for many important covariates (e.g., age, sex, smoking status, symptoms post SIC test, and prescribed dose of inhaled corticosteroid).

\section{Conclusion}

In summary, our study demonstrated interesting and novel links between depression, ANS-influenced measures of lung function $\left(\mathrm{FEV}_{1}\right)$ and immune markers in an understudied population of participants undergoing testing for OA. Overall, our results suggests that depression is potentially associated with attenuated ANS responses, particularly in participants with $\mathrm{OA}$, and with dysregulated immune responses that are more pronounced in participants without asthma. These results add to the extant literature linking depression to altered physiological response patterns. Findings suggest that depression may influence respiratory and immune responses to pulmonary function and SIC tests among participants undergoing evaluation for $\mathrm{OA}$, indicating that depression screening may be warranted to improve interpretation of diagnostic findings. 


\section{References}

1 Subbarao P, Mandhane PJ, Sears MR. Asthma: epidemiology, etiology and risk factors. CMAJ 2009; 181:E181-190

2 CDC National Center for Health Statistics. Asthma prevalence, health care use and mortality: United States, 2003-2005, Available at: https://www.cdc.gov/nchs/data/hestat/asthma0305/asthma03-05.htm. Date accessed: 14/12/2018

3 Torén K, Blanc PD. Asthma caused by occupational exposures is common - A systematic analysis of estimates of the population-attributable fraction. BMC Pulm Med 2009; 9:7

4 Bernstein IL, Chan-Yeung M, Malo JL. Asthma in the workplace. 2nd edition ed. New York:: Marcel Dekker Inc.;, 1999;

5 Mapp CE, Boschetto P, Maestrelli P, Fabbri LM. Occupational asthma. Am J Respir Crit Care Med 2005; 172:280-305

6 Lazarus RS, Folkman S. Stress, appraisal, and coping. New York: Springer, 1984;

7 Lavoie KL, Joseph M, Bacon SL. Psychological distress and occupational asthma. Curr Opin Allergy Clin Immunol 2009; 9:103-109

8 American Psychiatric Association. Diagnostic and Statistical Manual of Mental Disorders, Fifth Edition (DSM-5). Washington, DC: American Psychiatric Publishing, 2013; 
9 Yacoub MR, Lavoie K, Lacoste G, et al. Assessment of impairment/disability due to occupational asthma through a multidimensional approach. Eur Respir J 2007; 29:889896

10 Lavoie KL, Bacon SL, Barone S, et al. What's worse for asthma control and quality of life: Depressive disorders, anxiety disorders, or both? Chest 2006; 130:1039-1047.

11 Lavoie KL, Joseph M, Favreau H, et al. Prevalence of Psychiatric Disorders among Patients Investigated for Occupational Asthma. An Overlooked Differential Diagnosis? Am J Respir Crit Care Med 2013; 187:926-932

12 Rimington LD, Davies DH, Lowe D, Pearson MG. Relationship between anxiety, depression, and morbidity in adult asthma patients. Thorax 2001; 56:266-271

13 Lavoie KL, Cartier A, Labrecque M, et al. Are psychiatric disorders associated with worse asthma control and quality of life in asthma patients? Respir Med 2005; 99:1249-1257

14 Kaptein AA. Psychological correlates of length of hospitalization and rehospitalization in patients with acute, severe asthma. Soc Sci Med 1982; 16:725-729

15 Janson C, Bjornsson E, Hetta J, Boman G. Anxiety and depression in relation to respiratory symptoms and asthma. Am J Respir Crit Care Med 1994; 149:930-934

16 Krommydas GC, Gourgoulianis KI, Angelopoulos NV, et al. Depression and pulmonary function in outpatients with asthma. Respir Med 2004; 98:220-224 
17 Duivis HE, de Jonge P, Penninx BW, et al. Depressive symptoms, health behaviors, and subsequent inflammation in patients with coronary heart disease: prospective findings from the heart and soul study. The American Journal of Psychiatry 2011; 168:913-920

18 Gimeno D, Kivimaki M, Brunner EJ, et al. Associations of C-reactive protein and interleukin-6 with cognitive symptoms of depression: 12-year follow-up of the Whitehall II study. Psychol Med 2009; 39:413-423

19 Howren MB, Lamkin DM, Suls J. Associations of depression with C-reactive protein, IL-1, and IL-6: a meta-analysis. Psychosom Med 2009; 71:171-186

20 Krishnadas R, Cavanagh J. Depression: an inflammatory illness? Journal of Neurology, Neurosurgery, and Psychiatry 2012; 83:495-502

21 Krogh J, Benros ME, Jørgensen MB, et al. The association between depressive symptoms, cognitive function, and inflammation in major depression. Brain Behav Immun 2014; 35:70-76

22 Maes M. Depression is an inflammatory disease, but cell-mediated immune activation is the key component of depression. Prog Neuropsychopharmacol Biol Psychiatry 2011; 35:664-675

23 Miller BD, Wood BL, Lim J, Ballow M, Hsu C. Depressed children with asthma evidence increased airway resistance: "vagal bias" as a mechanism? J Allergy Clin Immunol 2009; 124:66-73 e61-10 
24 Liu L, Coe C, Swenson CA, et al. School Examinations Enhance Airway Inflammation to Antigen Challenge. American Journal of Respiratory and Critical Care Medicine 2002; $165: 1062-1067$

25 Lavoie KL, Favreau H, Paine NJ, et al. Prospective Impact of Psychiatric Disorders on Employment Status and Health Care Use in Patients Investigated for Occupational Asthma. J Occup Environ Med 2016; 58:1196-1201

26 Spitzer RL, Williams JB, Kroenke K, et al. Utility of a new procedure for diagnosing mental disorders in primary care. The PRIME-MD 1000 study. JAMA 1994; 272:1749-1756

27 American Psychiatric Association. Diagnostic and Statistical Manual of Mental Disorders. 4th ed. Washington, DC: American Psychiatric Press, 1994;

28 First MB, Spitzer RL, Williams JB, Gibbon M. Structured Clinical Interview for DSM-IV (SCID). Washington, DC: American Psychological Association, 1995;

29 Racine G, Castano R, Cartier A, Lemiere C. Diagnostic Accuracy of Inflammatory Markers for Diagnosing Occupational Asthma. J Allergy Clin Immunol Pract 2017; 5:1371-1377 e1371

30 Miller MR, Hankinson J, Brusasco V, et al. Standardisation of spirometry. Eur Respir J 2005; $26: 319-338$

31 Juniper E, Cockcroft D, Hargreave FE. Histamine and Methacholine Inhalation Tests: A Laboratory Tidal Breathing Protocol. Lund, Sweden: Astra Draco AB, 1994 
32 Pizzichini E, Pizzichini MM, Efthimiadis A, et al. Indices of airway inflammation in induced sputum: reproducibility and validity of cell and fluid-phase measurements. Am J Respir Crit Care Med 1996; 154:308-317

33 Vandenplas O, Malo JL. Inhalation challenges with agents causing occupational asthma. Eur Respir J 1997; 10:2612-2629

34 Lavoie K, Joseph M, Favreau H, et al. Psychiatric Disorders among Patients under Investigation for Occupational Asthma. Prevalence and Impact on Employment Status and Health Service Use. Bibliothèque et Archives nationales du Québec: Institut de recherche Robert-Sauvé en santé et en sécurité du travail, 2014

35 Rubin DB. Multiple Imputation for Nonresponse in Surveys. New York: Wiley, 1987;

36 Barzi F, Woodward M. Imputations of Missing Values in Pratice: Results from Imputations of Serum Cholesterol in 28 Cohort Studies. Am J Epidemiol 2004; 160:34-45

37 Harrell FE. Regression Modeling Strategies: With Applications to Linear Models, Logistic Regression, and Survival Analysis. New York: Springer, 2001;

38 Van Lieshout RJ, Bienenstock J, MacQueen GM. A Review of Candidate Pathways Underlying the Association Between Asthma and Major Depressive Disorder. Psychosom Med 2009; 71:187-195

39 Lewis MJ, Short AL, Lewis KE. Autonomic nervous system control of the cardiovascular and respiratory systems in asthma. Respir Med 2006; 100:1688-1705 
40 Kop WJ, Stein PK, Tracy RP, et al. Autonomic nervous system dysfunction and inflammation contribute to the increased cardiovascular mortality risk associated with depression. Psychosom Med 2010; 72:626-635

41 Glassman AH, Bigger JT, Gaffney M, Van Zyl LT. Heart rate variability in acute coronary syndrome patients with major depression: influence of sertraline and mood improvement. Arch Gen Psychiatry 2007; 64:1025-1031

42 Carney RM, Howells WB, Blumenthal JA, et al. Heart rate turbulence, depression, and survival after acute myocardial infarction. Psychosom Med 2007; 69:4-9

43 van Zyl LT, Hasegawa T, Nagata K. Effects of antidepressant treatment on heart rate variability in major depression: a quantitative review. Biopsychosoc Med 2008; 2:12

44 Trueba AF, Simon E, Auchus RJ, Ritz T. Cortisol response to acute stress in asthma: Moderation by depressive mood. Physiol Behav 2016; 159:20-26

45 Bellia V, Sorino C, Catalano F, et al. Validation of FEV6 in the elderly: correlates of performance and repeatability. Thorax 2008; 63:60-66

46 Cartier A. Definition and diagnosis of occupational asthma. Eur Respir J 1994; 7:153-160

47 Cockcroft DW, Mink JT. Isocyanate-induced asthma in an automobile spray painter. Can Med Assoc J 1979; 121:602-604 
48 Leander M, Lampa E, Rask-Andersen A, et al. Impact of anxiety and depression on respiratory symptoms. Respir Med 2014; 108:1594-1600

49 Wang G, Wang L, Szczepaniak WS, et al. Psychological status in uncontrolled asthma is not related to airway hyperresponsiveness. J Asthma 2010; 47:93-99

50 Herbert TB, Cohen S. Depression and immunity: a meta-analytic review. Psychol Bull 1993; $113: 472-486$

51 Zorrilla EP, Luborsky L, McKay JR, et al. The relationship of depression and stressors to immunological assays: a meta-analytic review. Brain Behav Immun 2001; 15:199-226

52 Stewart JC, Rand KL, Muldoon MF, Kamarck TW. A prospective evaluation of the directionality of the depression-inflammation relationship. Brain Behav Immun 2009; 23:936-944

53 Kiecolt-Glaser JK, Glaser R. Depression and immune function: central pathways to morbidity and mortality. J Psychosom Res 2002; 53:873-876

54 Du YJ, Li B, Zhang HY, et al. Airway inflammation and hypothalamic-pituitary-adrenal axis activity in asthmatic adults with depression. J Asthma 2013; 50:274-281

55 Bratek A, Zawada K, Beil-Gawelczyk J, et al. Depressiveness, symptoms of anxiety and cognitive dysfunctions in patients with asthma and chronic obstructive pulmonary disease (COPD): possible associations with inflammation markers: a pilot study. J Neural Transm (Vienna) 2015; 122 Suppl 1:S83-91 
56 Liu LY, Coe CL, Swenson CA, et al. School Examinations Enhance Airway Inflammation to Antigen Challenge. Am J Respir Crit Care Med 2002; 165:1062-1067

57 Valkanova V, Ebmeier KP, Allan CL. CRP, IL-6 and depression: a systematic review and meta-analysis of longitudinal studies. J Affect Disord 2013; 150:736-744 
Table 1. Participant characteristics as a function of diagnostic group

\begin{tabular}{|c|c|c|c|c|c|c|}
\hline & $\begin{array}{l}\text { Occupational } \\
\text { Asthma } \\
(\mathrm{N}=40)\end{array}$ & $\begin{array}{c}\text { Non- } \\
\text { Occupational } \\
\text { Asthma } \\
(\mathrm{N}=37)\end{array}$ & $\begin{array}{c}\text { No } \\
\text { Asthma } \\
(\mathrm{N}=35)\end{array}$ & $\begin{array}{l}\text { F value or } \\
X^{2} \text { value }\end{array}$ & $\mathbf{p}$ & Missing $\mathbf{N}$ \\
\hline \multicolumn{7}{|l|}{ Sociodemographics } \\
\hline Age (years) & $41.16 \pm 12.48$ & $42.51 \pm 11.57$ & $40.01 \pm 10.02$ & 0.43 & .65 & 0 \\
\hline Years of Education & $11.2 \pm 3.25$ & $11.57 \pm 2.93$ & $11.97 \pm 2.27$ & 0.68 & .51 & 0 \\
\hline BMI $\left(\mathrm{kg} / \mathrm{m}^{2}\right)$ & $27.55 \pm 6.19$ & $27.78 \pm 5.81$ & $27.16 \pm 6.33$ & 0.09 & .91 & 1 \\
\hline Sex (\% Men, $[N])$ & $62.5[25]$ & $59.5[22]$ & $57.1[20]$ & 0.23 & .89 & 0 \\
\hline Cohabitation (\%[N]) & $52.5[21]$ & $64.9[24]$ & $65.7[23]$ & 1.77 & .41 & 0 \\
\hline $\begin{array}{l}\text { Presence of any psychiatric } \\
\text { disorder }(\%[N])\end{array}$ & $32.5[13]$ & $23.4[12]$ & $48.6[17]$ & 2.66 & .26 & 0 \\
\hline Depressive disorder (\%[N]) & $27.5[11]$ & $29.7[11]$ & $37.1[13]$ & 0.87 & .65 & \\
\hline Smoking status (\%[N]) & & & & 2.81 & .59 & 0 \\
\hline Current smoker & $20[8]$ & $32.4[12]$ & $28.6[10]$ & & & \\
\hline Past smoker & 35 [14] & $37.8[14]$ & 40 [14] & & & \\
\hline Never smoker & $45[18]$ & $29.7[11]$ & $31.4[11]$ & & & \\
\hline
\end{tabular}




\begin{tabular}{|c|c|c|c|c|c|c|}
\hline & $\begin{array}{l}\text { Occupational } \\
\text { Asthma } \\
(\mathrm{N}=40)\end{array}$ & $\begin{array}{c}\text { Non- } \\
\text { Occupational } \\
\text { Asthma } \\
(\mathrm{N}=37)\end{array}$ & $\begin{array}{c}\text { No } \\
\text { Asthma } \\
(\mathrm{N}=35)\end{array}$ & $\begin{array}{l}F \text { value or } \\
X^{2} \text { value }\end{array}$ & p & Missing $\mathbf{N}$ \\
\hline \multicolumn{7}{|l|}{ Clinical Characteristics } \\
\hline $\begin{array}{l}\text { Max \% drop in } \mathrm{FEV}_{1} \text { for } \\
\text { control day }\end{array}$ & $-3.75 \pm 4.00$ & $-5.05 \pm 4.30$ & $-3.01 \pm 2.82$ & 2.68 & .0735 & 4 \\
\hline $\begin{array}{l}\text { Max \% drop in } \mathrm{FEV}_{1} \text { for SIC } \\
\text { day }\end{array}$ & $-18.93 \pm 9.72$ & $-5.86 \pm 5.69$ & $-4.79 \pm 2.74$ & 49.55 & $<.001$ & 2 \\
\hline $\begin{array}{l}\text { Geometric Mean } \mathrm{PC}_{20} \\
(\mathrm{mg} / \mathrm{ml}) \text { - control day }\end{array}$ & $19.57 \pm 29.61$ & $7.42 \pm 13.29$ & $81.34 \pm 48.15$ & 44.68 & $<.0001$ & 13 \\
\hline $\begin{array}{l}\text { Geometric Mean } \mathrm{PC}_{20} \\
(\mathrm{mg} / \mathrm{ml}) \text { - SIC day }\end{array}$ & $15.39 \pm 32.28$ & $9.04 \pm 25.20$ & $92.39 \pm 44.09$ & 51.97 & $<.001$ & 21 \\
\hline $\begin{array}{l}\text { Total dose of inhaled } \\
\text { corticosteroids ( } \mu \mathrm{g} / \text { day) }\end{array}$ & $682.69 \pm 531.78$ & $921.88 \pm 771.04$ & $173.91 \pm 372.60$ & 10.36 & $<.0001$ & 31 \\
\hline $\begin{array}{l}\text { Taking short-acting asthma } \\
\text { medication }(\%[\mathrm{~N}])\end{array}$ & 80 [32] & 89.2 [33] & $68.6[24]$ & 4.7 & .095 & 0 \\
\hline $\begin{array}{l}\text { Taking inhaled } \\
\text { corticosteroids }(\%[\mathrm{~N}])\end{array}$ & 90 [36] & $86.5[32]$ & $51.4[18]$ & 18.5 & $<.001$ & 0 \\
\hline $\begin{array}{l}\text { Taking long-acting asthma } \\
\text { medication }(\%[N])\end{array}$ & 40 [16] & $62.2[23]$ & 22.9 [8] & 11.5 & .0032 & 0 \\
\hline
\end{tabular}




\begin{tabular}{|c|c|c|c|c|c|c|}
\hline & $\begin{array}{l}\text { Occupational } \\
\text { Asthma } \\
(N=40)\end{array}$ & $\begin{array}{c}\text { Non- } \\
\text { Occupational } \\
\text { Asthma } \\
(\mathrm{N}=37)\end{array}$ & $\begin{array}{c}\text { No } \\
\text { Asthma } \\
(\mathrm{N}=35)\end{array}$ & $\begin{array}{l}F \text { value or } \\
X^{2} \text { value }\end{array}$ & $\mathbf{p}$ & Missing N \\
\hline \multicolumn{7}{|l|}{ Immune markers } \\
\hline \multicolumn{7}{|l|}{ SIC day - sputum only } \\
\hline $\begin{array}{l}\text { Total sputum cell count for } \\
\text { SIC day }\left(10^{6} \mathrm{c} / \mathrm{g}\right)\end{array}$ & $5.90 \pm 6.36$ & $4.66 \pm 6.95$ & $2.39 \pm 4.57$ & 2.17 & .12 & 28 \\
\hline $\begin{array}{l}\text { Total sputum neutrophil } \\
\text { count for SIC day }\left(10^{6} \mathrm{c} / \mathrm{g}\right)\end{array}$ & $3.28 \pm 5.21$ & $3.01 \pm 6.16$ & $1.30 \pm 3.53$ & 1.06 & .35 & 28 \\
\hline $\begin{array}{l}\text { Total sputum eosinophils } \\
\text { count for SIC day }\left(10^{6} \mathrm{c} / \mathrm{g}\right)\end{array}$ & $0.71 \pm 0.94$ & $0.11 \pm 0.31$ & $0.02 \pm 0.03$ & 10.53 & $<.001$ & 28 \\
\hline $\begin{array}{l}\text { Total sputum lymphocytes } \\
\text { count for SIC day }\left(10^{6} \mathrm{c} / \mathrm{g}\right)\end{array}$ & $0.13 \pm 0.20$ & $0.10 \pm 0.16$ & $0.02 \pm 0.04$ & 2.98 & .0565 & 28 \\
\hline $\begin{array}{l}\text { Percentage sputum } \\
\text { neutrophil count for SIC day } \\
\left(10^{6} \mathrm{c} / \mathrm{g}\right)\end{array}$ & $45.76 \pm 24.87$ & $46.47 \pm 26.85$ & $39.01 \pm 23.12$ & 0.65 & .52 & 28 \\
\hline $\begin{array}{l}\text { Percentage sputum } \\
\text { eosinophils count for SIC day } \\
\left(10^{6} \mathrm{c} / \mathrm{g}\right)\end{array}$ & $12.21 \pm 14.48$ & $2.10 \pm 5.13$ & $10.7 \pm 1.87$ & 11.94 & $<.0001$ & 28 \\
\hline $\begin{array}{l}\text { Percentage sputum } \\
\text { lymphocytes count for SIC } \\
\text { day }\left(10^{6} \mathrm{c} / \mathrm{g}\right)\end{array}$ & $2.20 \pm 2.44$ & $1.88 \pm 2.13$ & $1.22 \pm 1.39$ & 1.45 & .24 & 28 \\
\hline
\end{tabular}




\begin{tabular}{|c|c|c|c|c|c|c|}
\hline \multicolumn{7}{|l|}{ SIC day - blood only } \\
\hline $\begin{array}{l}\text { Total blood neutrophil count } \\
\text { for SIC day }\left(10^{6} \mathrm{c} / \mathrm{g}\right)\end{array}$ & $0.64 \pm 0.13$ & $0.60 \pm 0.08$ & $0.60 \pm 0.11$ & 1.83 & .17 & 11 \\
\hline $\begin{array}{l}\text { Total blood eosinophils count } \\
\text { for SIC day }\left(10^{6} \mathrm{c} / \mathrm{g}\right)\end{array}$ & $0.03 \pm 0.03$ & $0.02 \pm 0.02$ & $0.03 \pm 0.04$ & 0.31 & .73 & 12 \\
\hline $\begin{array}{l}\text { Total blood lymphocytes } \\
\text { count for SIC day }\left(10^{6} \mathrm{c} / \mathrm{g}\right)\end{array}$ & $0.25 \pm 0.10$ & $0.30 \pm 0.07$ & $0.31 \pm 0.10$ & 2.95 & .060 & 12 \\
\hline
\end{tabular}

Presented as Mean \pm SD or Percent; Note: OA = occupational asthma; BMI = Body Mass Index; Max \% drop in FEV I $_{1}$ Maximum \% drop in forced expiratory volume in 1 second $\left(F E V_{1}\right)$, expressed as a percentage of the patient's predicted value to the test; $\mathrm{PC}_{20}=$ provocative concentration of methacholine causing a $20 \%$ fall in $\mathrm{FEV}_{1}$; ICS = inhaled corticosteroid steroid; SIC = Specific Inhalation Challenge 
Table 2. Mean immune cell counts in pre-SIC sputum, presented by diagnostic group and depressive disorder.

\begin{tabular}{|c|c|c|c|c|c|c|c|c|}
\hline & \multicolumn{2}{|c|}{ Occupational Asthma (OA) } & \multicolumn{2}{|c|}{ Non-Occupational Asthma (Non-OA) } & \multicolumn{2}{|c|}{ No Asthma (NA) } & \multirow[b]{2}{*}{$\begin{array}{c}\text { Main effect } \\
\text { of } \\
\text { depression }\end{array}$} & \multirow[b]{2}{*}{$\begin{array}{l}\text { Main effect } \\
\text { of asthma } \\
\text { diagnosis }\end{array}$} \\
\hline & No depression & Depression & No depression & Depression & No depression & Depression & & \\
\hline $\begin{array}{l}\text { Total cell } \\
\text { count for } \\
\text { SIC day } \\
\left(10^{6} \mathrm{c} / \mathrm{g}\right)\end{array}$ & $6.64 \pm 7.17$ & $2.47 \pm 1.94$ & $6.11 \pm 8.69$ & $3.48 \pm 3.32$ & $1.32 \pm 0.74$ & $1.84 \pm 1.18$ & $\begin{array}{c}\beta=-0.28 \pm \\
1.35 ; \\
95 \% \mathrm{Cl}=- \\
2.94- \\
2.37\end{array}$ & $\begin{array}{c}\beta=-1.05 \pm \\
1.35 ; \\
95 \% \mathrm{Cl}=- \\
2.66- \\
0.55 ;\end{array}$ \\
\hline $\begin{array}{l}\text { \% } \\
\text { eosinophils } \\
\text { count for } \\
\text { SIC day } \\
\text { sputum }\end{array}$ & $12.02 \pm 14.90$ & $10.63 \pm 9.53$ & $2.76 \pm 4.58^{\mathrm{ab}}$ & $5.25 \pm 8.43^{b}$ & $2.86 \pm 5.27^{\mathrm{ab}}$ & $6.06 \pm 7.38^{b}$ & $\begin{array}{c}\beta=0.09 \pm \\
1.87 \\
95 \% \mathrm{Cl}=- \\
3.57- \\
3.75\end{array}$ & $\begin{array}{c}\beta=-4.96 \pm \\
1.17 ; \\
95 \% \mathrm{Cl}=- \\
5.55-- \\
3.88 ;\end{array}$ \\
\hline
\end{tabular}

Note: ${ }^{a}$ indicates significantly different from OA, No depression $(p<.05) ;{ }^{b}=$ indicates significantly different from OA, Depression $(p<$

.05); 
Table 3. Mean immune cell counts in blood pre-SIC test, presented by diagnostic group and depressive disorder.

\begin{tabular}{|c|c|c|c|c|c|c|c|c|}
\hline & \multicolumn{2}{|c|}{ Occupational Asthma (OA) } & \multicolumn{2}{|c|}{ Non-Occupational Asthma (non-OA) } & \multicolumn{2}{|c|}{ No Asthma (NA) } & \multirow[b]{2}{*}{$\begin{array}{l}\text { Main effect of } \\
\text { depression }\end{array}$} & \multirow[b]{2}{*}{$\begin{array}{c}\text { Main effect of asthma } \\
\text { diagnosis }\end{array}$} \\
\hline & No depression & Depression & No depression & Depression & No depression & Depression & & \\
\hline $\begin{array}{l}\text { Total } \\
\text { neutrophil } \\
\text { count for } \\
\text { SIC day } \\
\left(10^{6} \mathrm{c} / \mathrm{g}\right)\end{array}$ & $0.621 \pm 0.125$ & $0.690 \pm 0.119$ & $0.594 \pm 0.080^{a}$ & $0.610 \pm 0.080$ & $0.574 \pm 0.099^{a}$ & $0.651 \pm 0.116^{b}$ & $\begin{array}{c}\beta=0.05 \pm 0.02 ; 95 \% \mathrm{Cl} \\
=0.01-0.10 ; p= \\
.013\end{array}$ & $\begin{array}{c}\beta=-0.028 \pm 0.01 ; 95 \% \mathrm{Cl} \\
=-0.06--0.001 ; p= \\
.044\end{array}$ \\
\hline $\begin{array}{l}\text { Total } \\
\text { eosinophils } \\
\text { count for } \\
\text { SIC day } \\
\left(10^{6} \mathrm{c} / \mathrm{g}\right)\end{array}$ & $0.027 \pm 0.026$ & $0.028 \pm 0.030$ & $0.023 \pm 0.019$ & $0.023 \pm 0.020$ & $0.027 \pm 0.045$ & $0.030 \pm 0.033$ & $\begin{array}{c}\beta=0.002 \pm 0.006 \\
95 \% \mathrm{Cl}=-0.01-0.01 \\
p=.70\end{array}$ & $\begin{aligned} \beta & =-0.00 \pm 0.00 ; 95 \% \mathrm{Cls} \\
& =-0.01-0.01 ; p=.99\end{aligned}$ \\
\hline $\begin{array}{l}\text { Total } \\
\text { lymphocytes } \\
\text { count for } \\
\text { SIC day } \\
\left(10^{6} \mathrm{c} / \mathrm{g}\right)\end{array}$ & $0.271 \pm 0.100$ & $0.219 \pm 0.102$ & $0.305 \pm 0.072^{a}$ & $0.270 \pm 0.055$ & $0.337 \pm 0.091^{\text {a }}$ & $0.254 \pm 0.097^{b}$ & $\begin{array}{c}\beta=-0.05 \pm 0.02 ; \\
95 \% \mathrm{Cl}=-0.09-- \\
0.02 ; p=.004\end{array}$ & $\begin{array}{c}\beta=0.03 \pm 0.01 ; 95 \% \mathrm{Cl}= \\
0.01-0.05 ; p=.010\end{array}$ \\
\hline
\end{tabular}

Note: ${ }^{a}=$ indicates significantly different from OA, Depression $(p<.05) ;{ }^{b}=$ indicates significantly different from NA, No depression $(p$

$<.05)$ 
Online supplement

S1. Total sputum immune markers for the SIC day, presented as a function of asthma diagnosis.

\begin{tabular}{|c|c|c|c|c|c|c|}
\hline & $\begin{array}{l}\text { Occupational } \\
\text { Asthma } \\
(\mathrm{N}=40)\end{array}$ & $\begin{array}{c}\text { Non- } \\
\text { Occupational } \\
\text { Asthma } \\
(\mathrm{N}=37)\end{array}$ & $\begin{array}{c}\text { No } \\
\text { Asthma } \\
(\mathrm{N}=35)\end{array}$ & $\begin{array}{l}\text { F value or } \\
X^{2} \text { value }\end{array}$ & $\mathbf{p}$ & Missing N \\
\hline \multicolumn{7}{|l|}{ Immune markers } \\
\hline \multicolumn{7}{|l|}{ SIC day - sputum only } \\
\hline $\begin{array}{l}\text { Total sputum cell count for } \\
\text { SIC day }\left(10^{6} \mathrm{c} / \mathrm{g}\right)\end{array}$ & $5.90 \pm 6.36$ & $4.66 \pm 6.95$ & $2.39 \pm 4.57$ & 2.17 & .12 & 28 \\
\hline $\begin{array}{l}\text { Total sputum neutrophil } \\
\text { count for SIC day }\left(10^{6} \mathrm{c} / \mathrm{g}\right)\end{array}$ & $3.28 \pm 5.21$ & $3.01 \pm 6.16$ & $1.30 \pm 3.53$ & 1.06 & .35 & 28 \\
\hline $\begin{array}{l}\text { Total sputum eosinophils } \\
\text { count for SIC day }\left(10^{6} \mathrm{c} / \mathrm{g}\right)\end{array}$ & $0.71 \pm 0.94$ & $0.11 \pm 0.31$ & $0.02 \pm 0.03$ & 10.53 & $<.001$ & 28 \\
\hline $\begin{array}{l}\text { Total sputum lymphocytes } \\
\text { count for SIC day }\left(10^{6} \mathrm{c} / \mathrm{g}\right)\end{array}$ & $0.13 \pm 0.20$ & $0.10 \pm 0.16$ & $0.02 \pm 0.04$ & 2.98 & .0565 & 28 \\
\hline
\end{tabular}


Table S2. FEV 1 responses, presented by asthma diagnosis and depressive disorder

\begin{tabular}{|c|c|c|c|c|c|c|c|c|}
\hline & \multicolumn{2}{|c|}{ Occupational Asthma (OA) } & \multicolumn{2}{|c|}{ Non-Occupational Asthma (Non-OA) } & \multicolumn{2}{|c|}{ No Asthma (NA) } & \multirow[b]{2}{*}{$\begin{array}{c}\text { Main } \\
\text { effect of } \\
\text { asthma } \\
\text { aroup }\end{array}$} & \multirow[b]{2}{*}{$\begin{array}{c}\text { Main effect } \\
\text { of } \\
\text { depressive } \\
\text { disorder }\end{array}$} \\
\hline & No depression & Depression & No depression & Depression & No depression & Depression & & \\
\hline $\begin{array}{l}\mathrm{FEV}_{1} \\
\text { reactivity } \\
(\%)\end{array}$ & $-21.54 \pm 8.51$ & $-12.05 \pm 9.70$ & $-6.42 \pm 6.52$ & $-4.55 \pm 2.75$ & $-4.96 \pm 4.09$ & $-4.89 \pm 1.88$ & $\begin{array}{c}\beta=7.56 \pm \\
0.95 \\
95 \% \mathrm{Cl}= \\
5.68- \\
9.45 \\
p<.001\end{array}$ & $\begin{array}{c}\beta=3.59 \pm \\
1.53 \\
95 \% \mathrm{Cl}= \\
0.57-6.60 \\
p=.0195\end{array}$ \\
\hline
\end{tabular}


Table S3. Total mean immune cell counts in sputum pre-SIC test, presented by diagnostic group and depressive disorder.

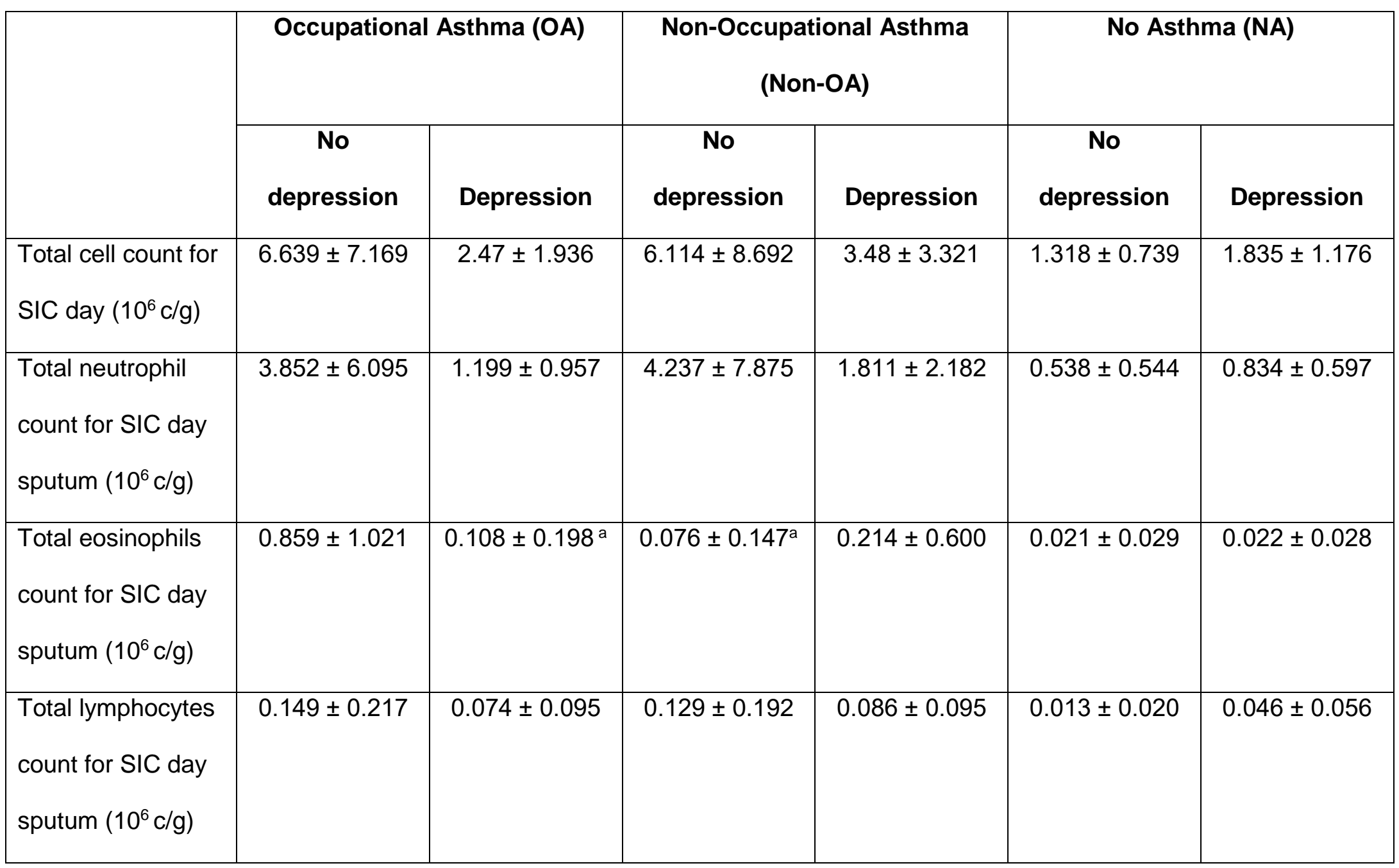




\section{Figure 1. Flow chart of participants}

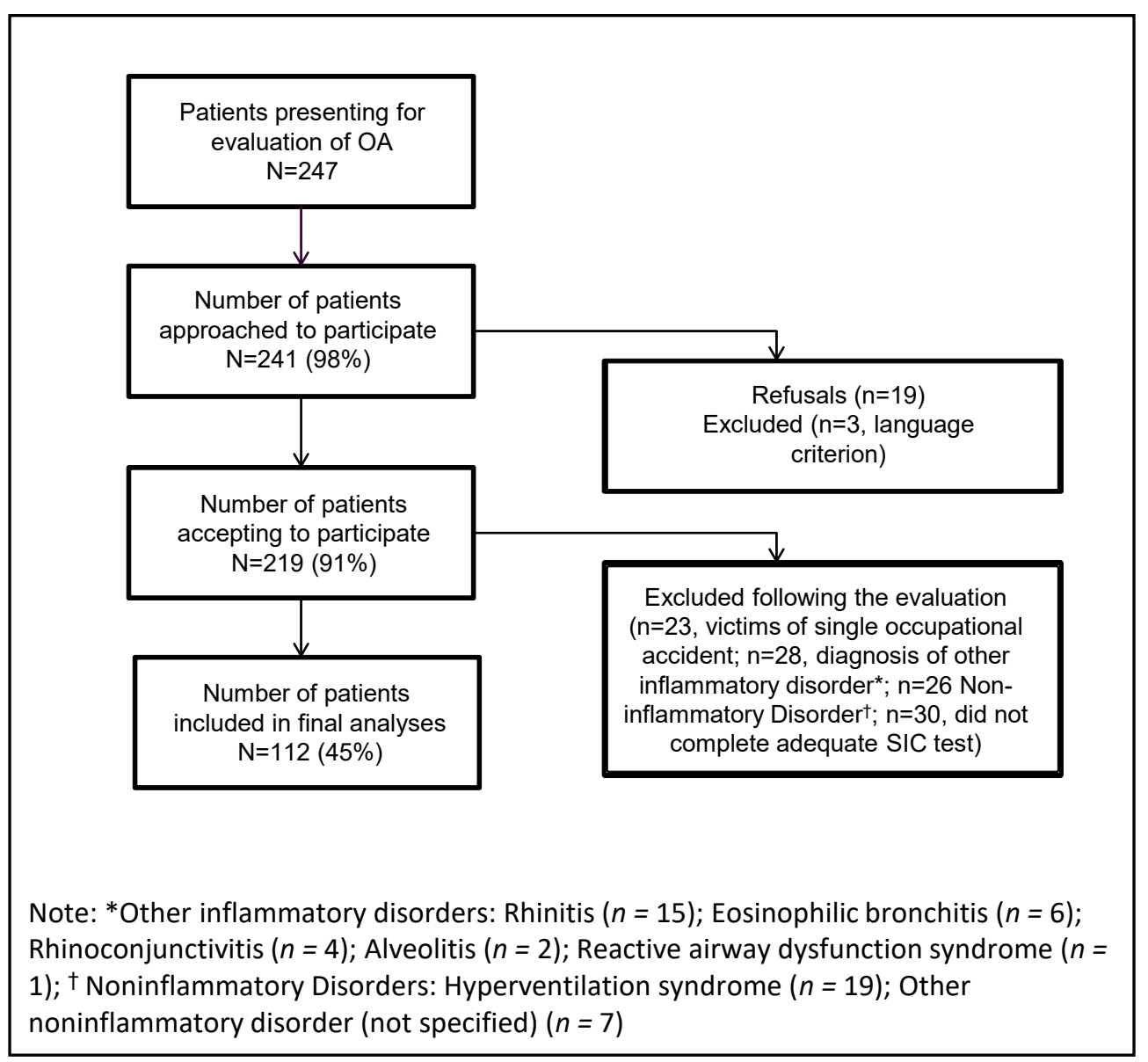


Figure 2. $\mathrm{FEV}_{1}$ responses (\% decrease) by Asthma diagnosis and Depressive Disorder

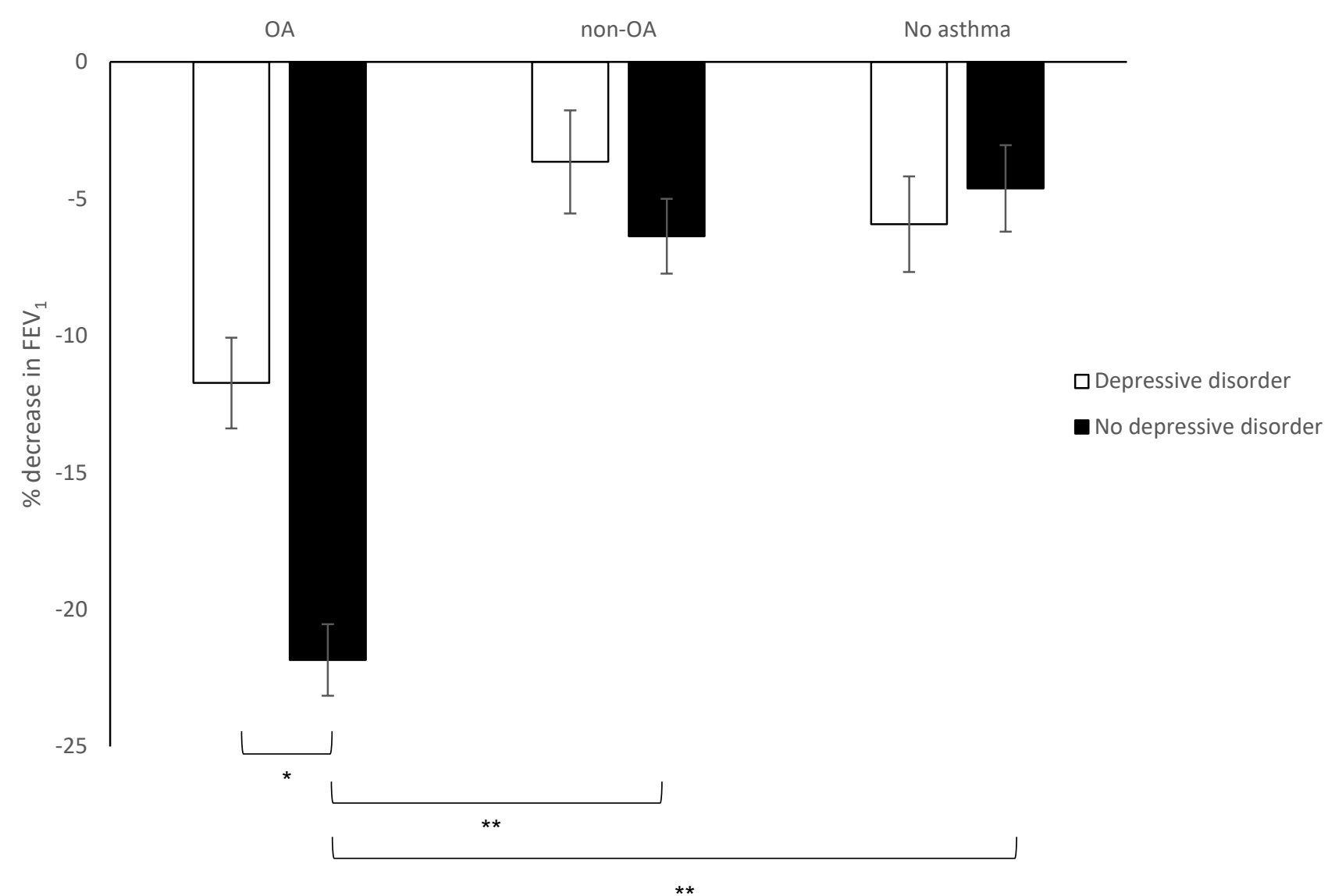

Note: ${ }^{*}=$ significantly different from no depressive disorder $(p<.001) ;{ }^{* *}=$ significantly different from OA, no depressive disorder $(p<.05)$ 